\title{
Children's perception of safety and danger on the road
}

\author{
Kwame Ampofo-Boateng and James A. Thomson* \\ Department of Psychology, University of Strathclyde, Glasgow, Scotland
}

\begin{abstract}
This study investigates the ability of children between 5 and 11 years to select safe places to cross the street. The children were presented with situations which were either extremely safe or manifestly dangerous and were asked to correctly identify these. In other cases, they were asked to choose for themselves routes across the road which they thought would be safe. The tasks were presented in various ways: by means of a table-top simulation on which traffic scenarios had been contrived; by means of photographs of road situations; and by taking the children to realworld sites in the streets near their schools. All the experiments showed a similar pattern of results. Five- and 7-year-olds exhibited very poor skill in identifying dangerous road-crossing sites. Their judgements relied exclusively on the visible presence of cars in the vicinity. Other factors such as blind summits, obscuring obstacles or complex junctions were never recognized as threatening situations. They also showed an unwillingness to make detours when planning their own routes, even where the direct route was manifestly dangerous. Nine-year-olds showed a higher level of ability and 11-year-olds showed quite good skill in these judgements. No sex differences were apparent. These results suggest that young children up to about 9 years must often be at considerable risk as they do not have the ability to recognize a location as dangerous, even if they know the mechanics of the Green Cross Code. The implications for road safety education are discussed.
\end{abstract}

Pedestrian road accidents constitute one of the most serious threats to children in the modern world. Such accidents are particularly high among 5-9-year-olds who suffer up to four times the casualty rate of adults (Department of Transport, 1988). A striking feature of casualty lists is the marked sex difference: over twice as many boys as girls are involved in pedestrian accidents at all levels of severity (Foot, Chapman \& Wade, 1982). A key problem for road safety research is to explain these regularities and devise training programmes to overcome them.

Not surprisingly, most countries have introduced educational measures to combat these trends. In Britain, this comes in the form of the Green Cross Code which constitutes the main theme of road safety education for children at the present time (Singh, 1982). The Code is a set of simple rules designed to provide children with basic information about the need for care when crossing the road together with an elementary strategy for doing so. Unfortunately, the success rate of this and similar counter-measures attempted to date can only be described as discouraging. Although a reduction in accidents did occur shortly after the Code's introduction (Morris,

* Requests for reprints. 
1972), this was confounded with many other factors that might equally have been expected to reduce the accident rate (Sheehy \& Chapman, 1984; Singh, 1982). No formal study using control groups was conducted, so assessing its contribution is extremely difficult. At any event, whatever the benefits of the Code the continuing scale of the problem shows that counter-measures still have a long way to go.

In our view, a major shortcoming of education measures at the present time is that they are seldom founded on a firm assessment of the skills required for successful road behaviour. As a result, it is unclear what skills should be taught. As an example, Lee, Young \& McLaughlin (1984) have attempted to specify in detail the perceptuomotor skills necessary in road crossing. These go far beyond the simple rules of the Green Cross Code and include the ability to judge visually the time-to-contact of oncoming vehicles; as well as the motor skills required in relating this information to one's own potential actions so that one can determine whether there is time to cross before the vehicle arrives. Such skills appear to be poorly developed in young children but can be improved with practice (Young \& Lee, 1987). This study highlights the sophistication of the skills required in road crossing and shows how inadequate an approach based on simple rules is likely to be, at least as the main strand in safety education. It also shows how indispensable is a clear theoretical perspective in regard to defining the skills that need to be taught in the first place.

The present paper is concerned with a related and equally important skill that has not been properly recognized in current safety education. This concerns the child's ability to identify locations or situations on the road that are intrinsically dangerous and where crossing should not be attempted (or where a special strategy is needed). The Green Cross Code or even the skills discussed by Lee et al. (1984) are of little value if the child attempts to put them into practice on the brow of a hill, for example. The Green Cross Code simply instructs the child to 'first find a safe place', which implies that children know a safe site when they see one. The Code's teaching notes do offer examples but these are mainly 'official' crossing facilities such as subways, pedestrian crossings and the like. However, the majority of child accidents occur on minor roads (Howarth \& Lightburn, 1980) and 60 per cent of them occur within $\frac{1}{4}$ mile of the child's own home (Grayson, 1975). These are precisely the areas where such crossing facilities are least likely to be found (Richards, 1974) and where children are consequently forced to rely on their own skills. If children are unable to distinguish safe places from dangerous ones, then the young child must often be at risk even in quiet suburban areas. Ironically, these are the very areas where parents are most likely to think that their children can cope on their own.

We have recently examined accident sites in areas of Glasgow with known high accident prevalence and observed not only that accidents do tend to occur in suburban areas but also that certain sites crop up repeatedly. Particularly common are locations where visibility would be restricted (e.g. at bends, near parked cars or other obstacles); or complex configurations such as junctions, crossroads and other intersections where traffic might arrive from a number of directions (thereby taxing the child's search and information-processing capacities) (Ampofo-Boateng \& Thomson, 1990). Similar findings have been obtained in studies elsewhere (ONSER, 1982). These regularities are certainly consistent with our hypothesis that children fail to recognize the dangers posed by such locations and are poor at selecting safe 
ones. Of course, if drivers travel too fast to stop within the limits of their own restricted vision at such sites, this would compound the risk to the child. There seems every reason to assume that this occurs quite commonly.

The present series of experiments, then, addresses three key questions in relation to this global hypothesis :

(1) How successfully can children differentiate safe from dangerous road-crossing sites? How safe are the routes which they select for themselves when asked to cross the road?

(2) What sex and age trends characterize these abilities?

(3) Which environmental features pose most difficulty in terms of danger identification?

\section{General method}

Our general approach was to present children with two standard tasks in each experiment, comprising a recognition and a construction task respectively. In the former, children were presented with a range of sites which were either completely safe or manifestly dangerous. Their task was to determine in various ways which was which. In the construction task, similar situations were presented but in this case the children had to select a safe route for themselves. The situations were all matched as far as possible for factors such as the overall complexity of the sites and surrounding layout. The sites included junctions, bends, parked cars or other obstructions. We also included a zebra crossing, because misinterpretation of its purpose has been observed to result in accidents (Van der Molen, 1981 ; Vinje, 1981). This arises where pedestrians cross close to, but not on, the crossing, apparently assuming that 'a band of safety' extends beyond the crossing itself. Accordingly, in one case the presented site was close to the crossing (not, of course, at the crossing itself).

In constructing the sites, care was taken that each was rendered dangerous by the presence of only one of these features. Our basic hypothesis was that young children would have difficulty with all such sites.

Selection of the sites in both tasks was done with the aid of four Road Safety Officers from Strathclyde Region's Department of Road Safety. A range of possible situations was presented to the officers who independently evaluated them. Only situations which showed 100 per cent agreement as to their manifest safety or danger were selected for use.

\section{EXPERMENT 1}

\section{Method}

\section{Subjects}

A total of 64 children aged 5, 7,9 and 11 years were selected from Glasgow schools. The mean ages of the children in each group were 5 years 6 months; 7 years 5 months; 9 years 5 months; and 11 years 6 months.

\section{Design and procedure}

The method involved the use of a large traffic mat measuring approximately $120 \times 100 \mathrm{~cm}$. It comprised a street layout on which a range of buildings, trees, bushes, hedges, toy cars and pedestrians were placed 
Table 1. Mean correct recognition of safe and dangerous sites to cross the road by age $(\max .=10)$

\begin{tabular}{lcccc}
\hline & \multicolumn{4}{c}{ Age (years) } \\
\cline { 2 - 5 } Road-crossing sites & 5 & 7 & 9 & 11 \\
\hline Safe & 8.67 & 8.25 & 9.06 & 8.63 \\
Dangerous & 5.13 & 6.13 & 8.56 & 8.75 \\
\hline
\end{tabular}

to create situations similar to those the children might encounter in the real traffic environment. The original materials were made in the laboratory but much higher quality ones were later constructed by a local toy-making factory. We did not discern any differences in the children's responses as a function of the test materials.

Each child completed 10 recognition tasks, five at safe and five at dangerous sites. Sites were designed as described in the General Method. Each child also completed four construction tasks in which they chose for themselves a safe route by which to cross. The order of presentation of the tasks was randomized.

In the recognition task, the toy pedestrian was positioned near to each of the road-crossing locations and the child was asked to judge whether it was safe or dangerous to cross there. The child was then asked to give reasons for his/her judgement. In the construction task, the starting point was similar but in this case the child was asked to walk the doll along a route it thought would be safe to get to a desired position on the other side. It was made clear that the route could be as circuitous as necessary to maintain safety. The experimenter marked the chosen route on a scale diagram of the model and then asked the child to justify the route. Verbal responses were recorded for later transcription.

Scoring was done in a different way for the two tasks. In the recognition task, subjects scored 1 if they correctly identified the site as safe or dangerous. A further 1 could be obtained if the verbal explanation showed some element of appreciation of the danger. Hence, a child's score on each trial could vary between 0 and 2 .

In evaluating the routes chosen in the construction task, a four-point scale from 1 (very unsafe) to 4 (very safe) was used. The verbal justifications were evaluated using a similar four-point scale. A child's score for each situation could thus vary between 1 and 8 .

All responses were independently assessed by the road safety officers, a final rating being determined by majority consensus following a later meeting.

\section{Results}

Recognition task. Table 1 shows the mean scores as a function of age and road crossing site. A 4 (age $5,7,9$ and 11) $\times 2$ (sex) $\times 2$ (safe or dangerous sites) analysis of variance (ANOVA) showed significant main effects of age $(F(3,36)=9.8, p<.001$ ) and road crossing site $(F(3,56)=15.42, p<.001)$. This indicates that ability to assess the danger of a crossing site improves with age. No effect of sex was established $(F(1,56)$ $=1.76$, n.s.). A significant interaction was obtained between age and road crossing site $(F(3,56)=4.63, p<.01)$.

It appears that whilst there is little difference between the groups in their ability to identify a safe location, the 5- and 7-year-olds frequently considered dangerous sites to be the safe ones. In fact, the younger children simply considered most sites to be safe. This was confirmed by post boc comparisons between the scores of the different age groups in both safe and dangerous conditions. In the safe condition, none of the intergroup differences proved significant. In the dangerous condition, no 

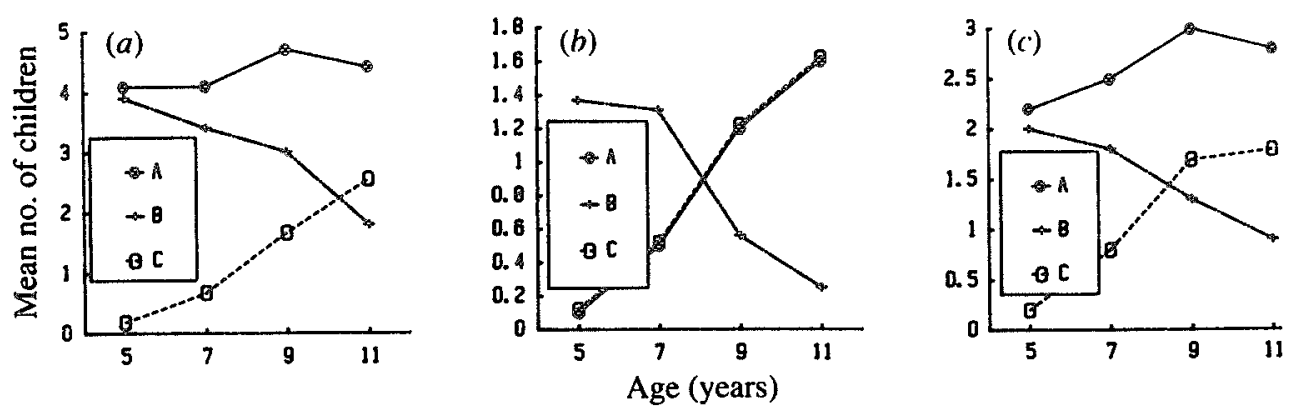

Figure 1. Breakdown of children's reasoning in Expt 1. A-mean number of children giving correct response; B-proportion of responses where presence or absence of cars was sole referent in estimating danger; $C$ - proportion of responses where other relevant road features were invoked.

difference emerged between the 9- and 11-year-olds, but the difference between these groups and both 5 -year-olds $(t=5.7, p<.001)$ and 7 -year-olds $(t=3.9, p<.001)$ was significant. The difference between 5 - and 7 -year-olds was not reliable.

The effect of road environmental features. A brief analysis was made to find out which of the five road environmental features may have caused most difficulty for the children in recognizing danger. The 5- and 7-year-olds were worse than the 9- and 11-yearolds at the parked car, hedge and junction. No differences emerged between the groups for the bend or zebra crossing.

Qualitative analysis of children's reasoning in the recognition task. The explanations children gave for their identification of a site as safe or dangerous were looked at for each group and each environmental feature. There emerged from this analysis a clearly defined age trend: the younger the children, the more likely they were to base their evaluation on a single factor - the presence or absence of cars on the road. In fact, if a car was to be seen anywhere remotely in the vicinity of the location, the younger children judged the situation to be dangerous. Conversely, however, if no cars were present at all (as was often the case), the younger children simply judged the site to be safe. They seldom took account of other critical factors, such as whether the doll's view of the road was blocked or not. Older children, on the other hand, based their decisions on a more mature assessment of the situation, taking into account a range of critical road features. Figure $1 a$ shows the pattern of the children's verbal responses to the safe sites, broken down into: (A) the total number of correct verbal responses for each age group; (B) the proportion of those responses where the decision was based on the absence of cars on the road; and $(C)$ the proportion where other road environmental features were taken into account. The tendency of the younger children to fixate on the presence of cars is clear: only with increasing age did they begin to take other factors into account.

A similar pattern was observed in the recognition of dangerous locations. The pattern was more complicated in this case, however, because sometimes cars were present on the model thereby biasing the children to judge such situations dangerous. This response would be correct (the situation was dangerous) but would be made for the wrong reason. The cars were on the model just to make the set-up look more realistic and were never positioned so as to be a cause for concern. Entirely separate 
factors rendered the site dangerous. The younger children, however, invariably focused on the cars and never invoked other factors. At the retrospective meeting, however, the Road Safety Team decided that these answers could not be regarded as entirely wrong since absolute safety could not be guaranteed in any environment where cars were moving about. Eventually, it was decided to score such justifications as correct. Thus in Figs. $1 b$ and $1 c$ we have separated those situations where cars were and were not present on the model. Where cars were present (Fig. 1c), the sites were judged dangerous on the basis of the cars. Where they were absent (Fig. 1b), it can be seen that the younger children judged dangerous sites to be safe. Only the older children made reference to the obstructions, intersections or other features which added a danger element to the situation. This fixation on cars explains the particularly poor performance of the 5- and 7-year-olds at the parked car, hedge and junction: in these particular set-ups, there were no cars on the model. Correspondingly, the apparently better judgements at the bend and zebra crossing were made for the wrong reasons: the answers were correct but were based on the presence of cars somewhere on the model rather than on an appreciation of the dangers inherent in those sites. The latter seemed to elude them completely.

Construction task. Table 2 shows the mean scores for constructed safe routes obtained by each age group. A 4 (age) $\times 2$ (sex) $\times 4$ (road-crossing location: hedge, junction, bend or zebra crossing) ANOVA showed a significant main effect of age $(F(3,56)=$ $52.75, p<.001)$ and road crossing location $(F(3,168)=7.5, p<.001)$. The interaction between road crossing site and age was also significant $(F(9,168)=3.2$, $p<.001)$. However, there was no significant effect of $\operatorname{sex}(F(3,56)=0.21$, n.s.). Post boc analyses showed that, overall, the children constructed more safe sites at the zebra crossing and hedge than at the other sites.

Table 2. Mean constructed safe routes by age and road-crossing site (max. $=8$ on each feature)

\begin{tabular}{cccccc}
\hline & \multicolumn{4}{c}{ Road-crossing sites } \\
\cline { 3 - 6 } & Age & & & Zebra \\
(years) & Hedge & Junction & Bend & crossing \\
\hline 5 & 4.06 & 3.63 & 2.88 & 5.00 \\
7 & 5.94 & 5.88 & 5.88 & 5.50 \\
9 & 6.75 & 6.13 & 6.44 & 7.25 \\
11 & 7.13 & 6.69 & 6.63 & 7.13 \\
\hline
\end{tabular}

Qualitative analysis of children's reasoning in the construction task. The pattern of explanations given for the chosen routes was also examined. As would be expected from the recognition scores, the responses of the 5- and 7-year-olds offered little insight into the dangers posed by the road environment. The 9 - and 11-year-olds, on the other hand, gave more mature explanations showing much better appreciation of the factors determining safety. 


\section{Discussion}

The results of Expt 1 strongly suggest that both the ability to recognize the danger inherent in certain road-crossing situations and the ability to choose a safe route develop as the child grows older. By 11 years of age, children are beginning to show a good deal of appreciation of such road danger. Younger children under the age of 9 , however, show remarkably little awareness of the factors that pose danger to the road-crossing pedestrian.

One confounding factor that might be felt partly to account for the age effects should be considered at this point. Half the scores in this study are based on the verbal justifications given by each child in support of their choices. If the 5- and 7year-olds were less able to articulate their reasoning than older children, this might introduce a bias towards poor scores that would reflect verbal skills rather than safety knowledge. In fact, we were sensitive to this possibility from the outset and the questioning was carefully conducted with this in mind. However, whilst differences in verbal fluency undoubtedly existed, these did not seem to explain to any degree the age effects: in fact, the 5-year-olds were sometimes quite fulsome in their comments. The issue can be best tackled by omitting the verbal justification scores from the analysis altogether. When this is done, exactly the same pattern of results emerges. Thus, the effects do not appear to be an artifact of the child's verbal ability but reflect their judgements about road safety.

The explanations which the children gave for their judgements are particularly instructive from this point of view. These show that the younger children fixated on a single strategy for deciding whether or not it was safe to cross. If there was a car anywhere in the vicinity, however tangential to the road-crossing situation itself, they judged the situation dangerous. In itself, this might not seem an altogether bad strategy, as they might simply be setting a very conservative criterion of safety. Unfortunately, if no car was visible they almost always regarded the crossing point as eminently safe. Thus, positions with totally obscured views from which traffic might emerge at any moment were considered safe. Not until 9 years do children apparently feel that the brow of a hill or a sharp bend with obscuring obstacles are dangerous places to try applying the Green Cross Code. This suggests that wherever official crossing facilities are unavailable, young children must often be at considerable risk. There would appear to be a need for this aspect of road safety education to be far more stressed than it is at the moment - both to children and drivers.

In view of the well-established sex difference in vulnerability to road accidents, it is interesting to note the lack of any sex factor in our data. This applies equally to the recognition of a situation as dangerous and to the ability of the children to construct a safe route for themselves. There are, of course, many possible reasons for a sex bias in road accidents. Differences in the skills examined here, however, do not appear to be among them.

The table-top model proved immensely popular and was an excellent device for establishing and maintaining the children's interest in the tasks. As a device for assessment, and perhaps even for training in road safety, it has many appealing features. However, there is an inherent developmental problem in using models of 
this kind: they require the subjects to adopt the perspective of another observer. The problem is that, in many tasks, young children up to the age of 7 or 8 appear to have difficulty in taking another viewer's perspective when the latter occupies a different spatial position from themselves (Piaget \& Inhelder, 1956). Typically, children in this situation will attribute to the other observer the same perspective as they themselves enjoy. In the table-top task, of course, the child benefits from a bird's-eye view of the road layout whereas the doll pedestrian's view is obscured in various ways. It might reasonably be argued that the 5- and 7-year-olds have difficulty in recognizing the inherent danger in the situations because, from their own point of view, there is no problem of visibility up and down the road. The older children, on the other hand, with their superior ability to manipulate perspective, would perform better not because of superior road safety understanding, but simply because they can appreciate the importance of the visual obstacles more easily under the conditions of the present experiment. If the younger children viewed the road layout from the point of view of the doll pedestrian, it is possible that their difficulty in recognizing danger would reduce or even disappear.

In fact, the difficulty that young children experience in taking the perspective of another observer varies considerably with the task (see for example, Borke, 1984; Cox, 1980; Donaldson, 1978; Gzech \& Surber, 1985) and we designed Expt 1 with this in mind. However, because a strong element of doubt must remain, and because we were keen to investigate the potential of the table-top model as a device for training in precisely the youngest groups, we decided to assess the children's skills in situations where they did not need to decentrate. We did this by creating tasks where the children either viewed the road from the same perspective as the doll pedestrian (Expts 2 and 3); or where they made judgements for themselves whilst occupying positions on a real road (Expt 4). In this way, decentration problems were bypassed.

\section{EXPERIMENT 2}

Experiment 2 controlled decentration by offering subjects the same view of the road as the toy pedestrian whose safety they were to judge. In this way, conflict between their own and the doll's view was eliminated. This method also ensured that the children did not dispose of 'extra' information gleaned from the more comprehensive bird's-eye perspective they previously enjoyed. This was achieved by presenting the subjects with photographs of road-crossing situations taken from just behind the doll's back in such a way that the child and the doll received essentially the same view. The road-crossing situations were similar to those used in Expt 1 and were set up on the table-top model as before. Thus, apart from controlling for decentration, the situations were almost identical.

A further adjustment was to eliminate cars totally from the task (except for the parked car used as an obstruction). It was felt that this might discourage the younger children from using the presence of cars as their main referent of danger and might induce them spontaneously to seek other indicators. 
Table 3. Mean correct recognition of safe and dangerous road-crossing sites by age $(\max .=10)$

\begin{tabular}{lcccc}
\hline & \multicolumn{4}{c}{ Age (years) } \\
\cline { 2 - 5 } Road-crossing sites & 5 & 7 & 9 & 11 \\
\hline Safe & 9.75 & 8.00 & 7.29 & 8.67 \\
Dangerous & 1.08 & 2.83 & 6.42 & 8.08 \\
\hline
\end{tabular}

\section{Method}

\section{Subjects}

Forty-eight children aged 5, 7,9 and 11 years were selected as described above. None had participated in Expt 1. The mean ages were 5 years 4 months; 7 years 4 months; 9 years 4 months; and 11 years 3 months.

\section{Design and procedure}

Each situation was set up on the model in the same way as in Expt 1 and then shot from just behind the doll pedestrian using a Pentax LX camera and $50 \mathrm{~mm}$ macro lens. Each shot was arranged so that all relevant features were contained in the photograph and none was obscured by the doll in the foreground.

As before, the child completed 10 recognition and four construction tasks. In the latter, the children indicated a route the doll might safely take by moving a pointer over the photograph. The experimenter marked this on a master sheet for later analysis. In all other respects, the design was identical to Expt 1.

\section{Results}

Recognition task. The mean scores in identifying safe and dangerous locations are shown in Table 3. A 4 (age: 5, 7, 9 and 11) $\times 2$ (sex) $\times 2$ (safe vs. dangerous sites) ANOVA showed significant main effects of age $(F(3,40)=12.35, p<.001)$ and road-crossing location $(F(1,40)=57.91, p<.001)$ but not of sex. A significant interaction was also obtained between age and road-crossing site $(F(3,40)=10.31$, $p<.001)$.

As in Expt 1, little difference was found between the age groups in recognizing safe road-crossing locations. Identifying the dangerous locations, however, produced marked differences. Follow-up analyses on the dangerous sites showed the 5-yearolds to be significantly poorer than both the 9 -year-olds $(t=6.14, p<.001)$ and 11 year-olds $(t=4.15, p<.001)$. The 7-year-olds also performed more poorly than the 9 -year-olds $(t=2.59, p<.001)$ and 11 -year-olds $(t=4.20, p<.001)$. The difference between 5 - and 7-year-olds was not significant, nor was the difference between 9- and 11 -year-olds. These findings are thus strikingly similar to those observed in Expt 1. Post hoc analyses of the errors at the different road environmental features, show that the 5-and 7-year-olds made significantly more errors at every feature than the 9-and 11 -year-olds. 
(a) Safe sites

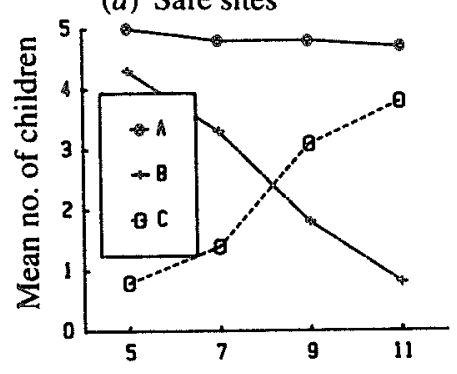

(b) Dangerous sites

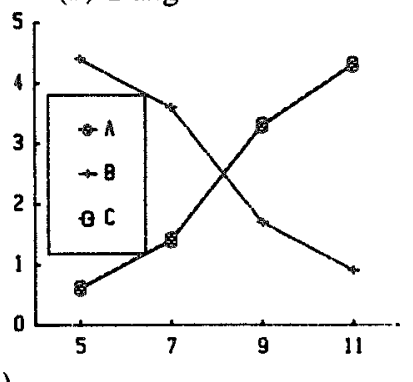

Figure 2. Children's reasoning in evaluating the sites in Expt 2. A-mean number of children giving correct response; B-proportion of responses where presence or absence of cars was the referent; $\mathrm{C}$-proportion of responses where reference was made to other features.

Qualitative assessment of cbildren's reasoning in the recognition task. The children's explanations are presented in Fig. 2. Again, the younger children were strongly inclined to rely on the visible absence of cars in assessing safety which led many dangerous sites to be misjudged as safe. Only the older children appeared to recognize that a road-crossing site may be dangerous precisely when no cars are visible, for example because they may be hidden from view.

Construction task. Table 4 shows the mean scores obtained by each age group on the construction task. A three-way ANOVA showed main effects of age $(F(3,40)=$ $26.67, p<.001)$ and road crossing-site $(F(3,120)=17.09, p<.001)$. There was no effect of sex, nor were any of the interactions significant.

Table 4. Mean constructed safe routes by age and road-crossing situation (max. $=8$ on each feature)

\begin{tabular}{ccccc}
\hline & \multicolumn{4}{c}{ Road-crossing sites } \\
\cline { 2 - 5 } $\begin{array}{c}\text { Age } \\
\text { (years) }\end{array}$ & Hedge & Junction & Bend & $\begin{array}{c}\text { Zebra } \\
\text { crossing }\end{array}$ \\
\hline 5 & 3.67 & 4.75 & 3.08 & 4.50 \\
7 & 3.75 & 5.08 & 3.25 & 5.33 \\
9 & 5.08 & 6.08 & 5.33 & 7.58 \\
11 & 6.58 & 6.50 & 6.83 & 8.00 \\
\hline
\end{tabular}

When the children's explanations were assessed, the pattern was again similar to Expt 1 with the younger children giving poor or irrelevant justifications for their routes. Only the older children showed a significant appreciation of the dangers to be taken into account. 


\section{Discussion}

Overall, the results of Expt 2 are in close agreement with those of Expt 1. As before, there was little difference between the age groups in identifying safe places to cross: the marked age effect was due to the inferior ability of the younger children to recognize dangerous sites. Again, this was due to the younger children's tendency to fixate on the presence or absence of cars. Since cars were never present in any of the conditions, this meant that the 5- and 7-year-olds were even more likely than in Expt 1 to judge dangerous sites as safe (cf. Tables 1 and 3). Incidentally, it is interesting to note that, whilst the younger children were biased towards judging dangerous sites as safe, we noted a slight tendency for older children to err in the opposite direction, producing 'false alarms' from time to time. By contrast, the younger children's strategy ensured they erred in the most dangerous direction.

The primary function of Expt 2 was to control for decentration. In spite of the removal of the perspective-taking skills required in the first experiment, the pattern of results was confirmed. This suggests that the effects obtained in Expt 1 did indeed reflect differences in road understanding rather than task-specific constraints due to the method used.

\section{EXPERIMENT 3}

The results of the preceding experiments suggest the younger children have only very rudimentary understanding of the dangers posed by the roadside environment. However, so far the subjects have been presented with situations individually and then asked to make a judgement. In such circumstances, the presence of cars appears to have a very high weighting with the 5 - and 7 -year-olds. Is it the case, however, that the children are completely unaware that there exist other criteria that might be used or are these merely overshadowed by their main criterion? To assess this, Expt 3 presented the tasks in such a way as to discourage the children from using the car criterion, so that they were forced to consider alternatives. This was achieved by presenting situations in pairs, one of which was always safe and the other dangerous. The children were told this and were then encouraged to say which was which. In this way we hoped to force any residual, even rudimentary, knowledge out of them.

\section{Method}

\section{Subjects}

Forty-eight children aged 5, 7, 9 and 11 were selected in the usual manner. None had participated in the preceding studies. The mean ages in each group were 5 years 7 months; 7 years 5 months; 9 years 6 months; and 11 years 6 months.

\section{Design and procedure}

Half the children performed the tasks on the table-top model and half received photographic stimuli. Assignment to these groups was randomized. The presented situations were identical on both tasks. Five pairs of recognition and four construction tasks were presented as before.

As the children were presented with a two-choice procedure, some differences from the preceding 
general method were introduced. In the recognition task, the children were simultaneously presented with paired road-crossing situations and were told that one was safe and one was dangerous. They had to decide which was the dangerous site. They were also asked to justify this choice. Thus, though under previous testing conditions the children might have felt both situations to be safe, they were here forced to search for features that might render one of them dangerous. In this way, any fragmentary road knowledge that might have been submerged in Expts 1 and 2 should have the opportunity to emerge.

In the construction task, the children were not asked to construct their own route as before but were asked to choose amongst four routes marked out on the photograph or model. Routes were either displayed on transparencies placed over the photographs or by cardboard arrows laid on the model. Each route was portrayed in a different colour. The routes varied on a scale from very safe to very unsafe as determined by the road-safety panel.

Scoring was similar to earlier experiments. In the recognition task, subjects received one point for identifying the dangerous site. They could obtain a further point by providing an acceptable justification for this choice. Scores could thus vary between 0 and 2 . Thus, in cases where a child insisted both sites were safe, as sometimes occurred, a score of 0 would be awarded. In the construction task, scoring was on the same eight-point scale as in the previous experiments.

\section{Results}

Recognition task. Table 5 shows the mean scores for the four age groups. A three-way ANOVA showed main effects for age $(F(3,40)=13.35, p<.001)$ and road-crossing site $(F(1,40)=51.86, p<.001)$ together with a significant interaction between age and road-crossing site $(F(3,40)=22.13, p<.001)$. There was no effect of testing method (model versus photographs).

Table 5. Mean correct recognition of safe and dangerous sites by age and task type $(\max .=10)$

\begin{tabular}{|c|c|c|c|c|c|}
\hline \multirow{2}{*}{$\begin{array}{l}\text { Road-crossing } \\
\text { site }\end{array}$} & \multirow{2}{*}{$\begin{array}{l}\text { Task } \\
\text { type }\end{array}$} & \multicolumn{4}{|c|}{ Age (years) } \\
\hline & & 5 & 7 & 9 & 11 \\
\hline Safe & $\begin{array}{l}\text { Photo } \\
\text { Model }\end{array}$ & $\begin{array}{r}9.33 \\
10.00\end{array}$ & $\begin{array}{r}10.00 \\
8.67\end{array}$ & $\begin{array}{l}9.83 \\
7.33\end{array}$ & $\begin{array}{l}8.50 \\
9.67\end{array}$ \\
\hline Dangerous & $\begin{array}{l}\text { Photo } \\
\text { Model }\end{array}$ & $\begin{array}{l}1.00 \\
3.00\end{array}$ & $\begin{array}{l}4.17 \\
5.83\end{array}$ & $\begin{array}{l}9.00 \\
8.00\end{array}$ & $\begin{array}{l}9.33 \\
9.67\end{array}$ \\
\hline
\end{tabular}

Post boc tests following the interaction between age and road-crossing site showed that the 5-year-olds performed significantly worse than 7-year-olds $(t=2.14$, $p<.05)$; 9-year-olds $(t=8.01, p<.001)$; and 11-year-olds $(t=10.09, p<.001)$. The 7-year-olds were also worse than the 9-year-olds $(t=2.72, p<.05)$; and 11 -year-olds $(t=3.61, p<.01)$. There was no difference between the oldest groups.

Qualitative analysis of children's justifications of responses. Figure 3 summarizes the reasoning the children offered for their judgements. Even though the children could not use the car criterion to differentiate safe from dangerous situations, they persisted in invoking this factor. Thus, they persisted in claiming that most of the sites were safe because there were no cars about. Being told by the Experimenter that one of 
the sites was nevertheless dangerous did not help them latch on to other factors and they simply insisted that both sites were safe. Only with age were a wider range of variables taken into consideration.

(a) Safe sites

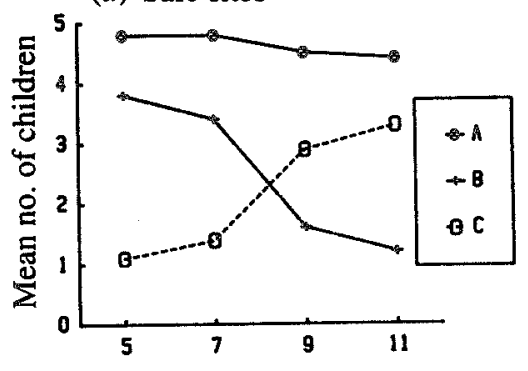

(b) Dangerous sites

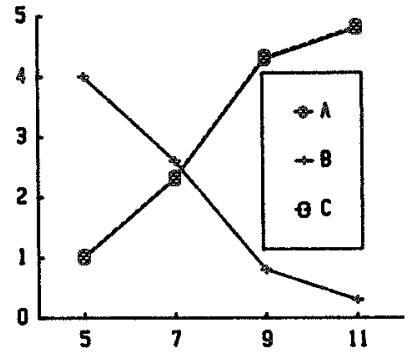

Age (years)

Figure 3. Children's reasoning in Expt 3. A-mean number of children giving correct response; $\mathrm{B}$-proportion of responses where presence or absence of cars was the referent; C-proportion of responses where reference was made to other relevant features.

Construction task. Table 6 shows the mean scores for each group on the construction task. A three-way ANOVA showed a main effect of age $(F(3.40)=18.41, p<.001)$ and road-crossing location $(F(3.120)=10.29, p<.001)$. No interactions were obtained. The effect of location seems to be due to the route involving a zebra crossing, which the children more often identifed as safe.

Table 6. Mean identified safe routes by age and task type (max. $=8$ on each feature)

\begin{tabular}{lccccc}
\hline & & \multicolumn{5}{c}{ Age (years) } \\
\cline { 3 - 6 } $\begin{array}{l}\text { Road-crossing } \\
\text { site }\end{array}$ & $\begin{array}{c}\text { Task } \\
\text { type }\end{array}$ & 5 & 7 & 9 & 11 \\
\hline Hedge & & 2.83 & 3.83 & 3.83 & 5.67 \\
Junction & & 3.33 & 3.83 & 4.50 & 5.67 \\
Bend & Photo & 2.83 & 3.33 & 5.83 & 4.83 \\
Zebra crossing & & 3.17 & 5.00 & 7.83 & 8.00 \\
Hedge & & 3.83 & 3.67 & 4.00 & 7.83 \\
Junction & & 3.16 & 3.17 & 5.67 & 6.67 \\
Bend & Model & 3.00 & 2.83 & 4.17 & 7.50 \\
Zebra crossing & & 3.50 & 5.17 & 5.33 & 7.67 \\
\hline
\end{tabular}

Qualitative assessment of the justifications given for route selection. A content analysis of the verbal responses showed once again that the younger children always justified their route by saying no cars were about. Only the older children took account of other factors.

Experiment 3 also controlled the scale value of the shortest and most direct route across all tasks. Figure 4, showing the age trend for choice of this route, confirms previous suspicions that the younger children were strongly inclined to identify the 
shortest route as safest. They would justify this by arguing that a car might come, apparently feeling that as short a time as possible should be spent on the road. This is, of course, in line with road-safety education and is true if the location is not a dangerous one. However, it is an obviously poor strategy if interpreted to mean that the route cannot be lengthened even by walking along the pavement to a safer position! Such an interpretation was typical of the children, evidencing once again their very rigid interpretation of such rules of thumb.

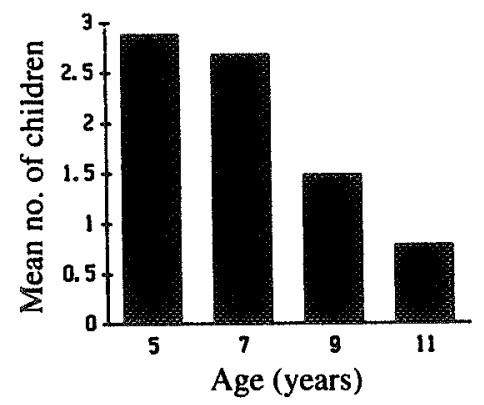

Figure 4. Mean number of children in each age group who selected the shortest route as safest in Expt 3.

\section{Discussion}

The results of Expt 3, then, show no significant deviations from the pattern of previous experiments. Once again, the 5- and 7-year-olds poorly identified dangerous crossing sites because of their fixation on the presence/absence of cars. The forcedchoice technique did not elicit any significant change in the range of factors they took into account. In the construction task, the two younger groups' tendency to consider the shortest, most direct route as safest, showed an almost complete lack of awareness of the dangerous role of obstacles or other intruding features on the safety of a crossing situation. The older children showed awareness of these, choosing alternative routes which reduced the dangers.

No significant differences were established between the table-top model and the photographic tasks in this experiment, where the stimuli were in all other respects identical. These results, taken together with the results of the earlier experiments, would suggest that the table-top model is a suitable device for investigating roadcrossing skills in children as young as 5 years and that the results obtained are unlikely to be confounded with egocentricity difficulties for the younger children.

These results have been very consistent and we are strongly inclined to suggest that they reflect genuine differences in road-crossing skill. However, it must always be conceded that classroom findings may not generalize to the real world. As a last strand in our argument, therefore, we decided to ask children to make safety judgements about sites in the real traffic environment. If the results obtained so far are attributable to artificial aspects of the task, these should then be eliminated. If the results were similar, on the other hand, this would greatly strengthen the conclusions that we have so far drawn. Of course, this experiment bypasses completely the egocentricity problems encountered with the table-top model. 


\section{EXPERIMENT 4}

\section{Method}

\section{Subjects}

As the older children continually demonstrated reasonable skill even in the classroom studies, we restricted the present experiment to 5- and 7-year-olds where there was more room for improvement. Twenty-four children were tested, 12 in each age group divided equally between boys and girls. The mean ages were 5 years 4 months and 7 years 3 months.

\section{Setting, design and procedure}

The overall design was similar to previous experiments, except that testing took place in the real traffic environment in the general vicinity of the children's schools. Each location was chosen to be as near as possible to real-life equivalents of those previously contrived on the table-top model. However, the zebra crossing was omitted as the children had shown good knowledge of this feature in previous experiments anyway. Locations were selected for their stable character; i.e. they did not change much from day to day making the sites comparable for different children. Children were never tested if, for example, a parked car had been introduced near the site thus distorting the feature layout. In such cases, testing would be conducted at a later date.

Each child completed eight recognition tasks (four safe and four dangerous) and three construction tasks. They were collected individually from the classroom by two male experimenters (one was a Road Safety Inspector) who accompanied them to the testing sites. All were within walking distance of the school. The Road Safety Officer's role was to oversee the procedure and intervene if he thought there might be risk to the child. Otherwise, he made his presence as unobtrusive as possible.

In the recognition task, the child was positioned at the preselected site and was asked whether this would be a safe place to cross. They were then asked to explain their answer. In the construction task, they were asked to choose for themselves a route which they considered safe. They did this simply by pointing to the route and describing it to the experimenter who marked it on prepared plans of the street. The children also explained why the route they chose was suitable. Questioning took place only when the road was clear of approaching traffic (though traffic might be visible, for example on the main road at the top of the street).

\section{Results}

Recognition task. The mean scores for each task are presented in Table 7. A two-way ANOVA with age and road-crossing site (safe/dangerous) as factors showed a significant effect of crossing site $(F(1,22)=21.42, p<.001)$ but no effect of age $(F(1,22)=0.31$, n.s. $)$. No interaction was obtained. Post boc analyses did not reveal any differences between the features used. As in previous experiments, there was also no effect of sex.

Table 7. Mean correct recognition of safe and dangerous road-crossing sites by age $(\max .=8)$

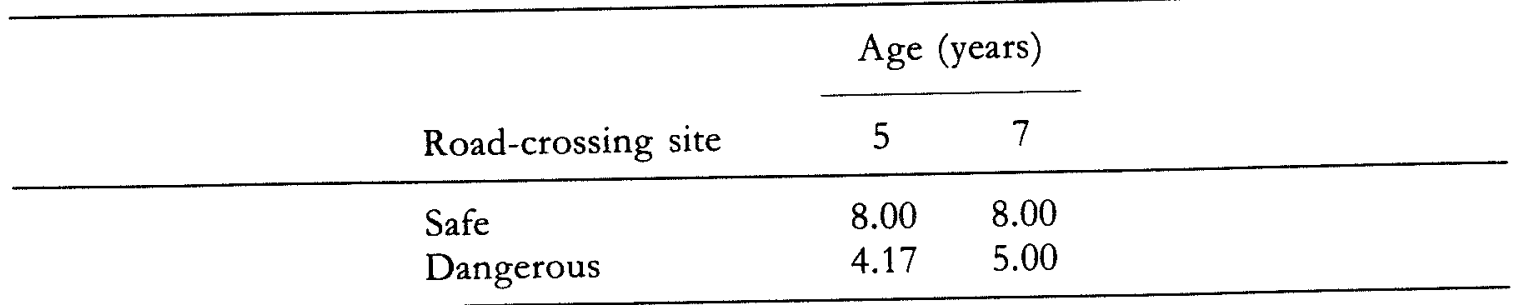


Figure 5 shows the explanations proposed by the children in making their judgements. As before, the children stuck to the presence or absence of cars in the immediate visible environment in making their judgements. It should be noted that, in the present experiment, a car would occasionally appear somewhere in the vicinity thus rendering the 'safe' sites 'dangerous'. Although such cars would always be distant and tangential to the task (no child was asked to make an estimate if a car was actually approaching), the children were scored as correct if they claimed the site was dangerous in these cases because of the conservative criterion adopted by the safety team. Figure 5 thus separates from the total 'correct' responses those where safety or danger was judged on the absence or presence of cars respectively. As in previous experiments, the car factor was the only one invoked to make their judgements : no other factors were, in fact, proposed at all.

(a) Safe sites

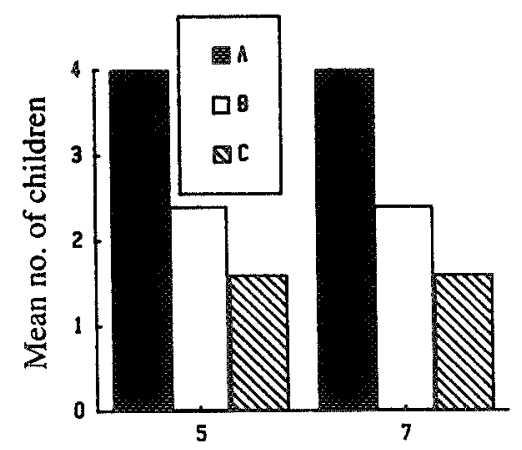

(b) Dangerous sites

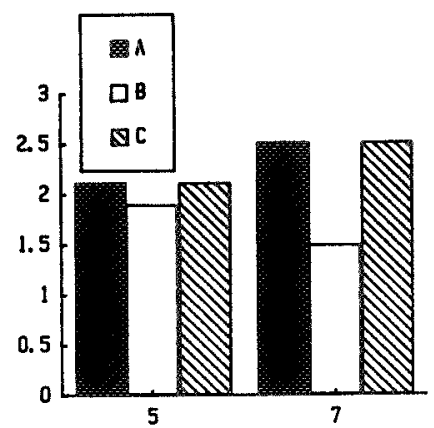

Age (years)

Figure 5. Children's reasoning in evaluating the sites in Expt 4. A-mean number of children giving correct response; B-number of children who used absence of cars to estimate that the road was safe; $C$-number of children who used presence of cars to estimate that the road was dangerous.

Construction task. Table 8 shows the results for each task. A significant effect of road site was again established $(F(2,44)=27.16, p<.001)$ but there was no effect of age. On the four-point scale used for categorizing the constructed routes, the children's explanations were mostly ranked 1 or 2 showing little insight into the dangers posed by the site. There were almost no class 4 responses at all. A disproportionately large number of class 3 responses was obtained due to the panel's decision to score as correct choices based on the presence of cars nearby. Almost all the responses in this category were of this type. As in the previous experiments, then, the presence of cars

Table 8. Mean constructed safe routes at each crossing site by age (max. $=8$ on each feature)

\begin{tabular}{|c|c|c|c|}
\hline \multirow{2}{*}{$\begin{array}{c}\text { Age } \\
\text { (years) }\end{array}$} & \multicolumn{3}{|c|}{ Road-crossing locations } \\
\hline & Obstructions & Junction & Bend \\
\hline 5 & 3.25 & 5.33 & 3.50 \\
\hline 7 & 3.75 & 5.58 & 4.08 \\
\hline
\end{tabular}


took on its usual weighting. There was no increased tendency for other features to figure when tested in the real traffic environment.

\section{Discussion}

Experiment 4, then, found no significant deviations from the results of previous experiments. The children again relied on the presence or absence of cars to make their judgements. Other important features were ignored.

\section{GENERAL DISCUSSION}

The major findings of the study appear to be as follows:

(1) Children aged 5 and 7 appear to determine the safety of a site purely on whether they can see cars on the road from the position they (or the doll pedestrian) currently occupy. No other cues were taken into account. As a result, they frequently judged as safe locations which were in fact potentially extremely dangerous. By age 9 , the children were demonstrating far more ability to detect such dangers, however, and by age 11 their overall road awareness seemed to have considerably improved.

(2) When asked to choose for themselves a safe route across the road, the younger children tended to select the shortest, most direct route as the safest. They justified this by saying that the journey would be quicker and time on the road therefore shorter. Unlike the older children, they again failed to take account of any of the inherent dangers posed by the local environmental layout.

(3) There was no evidence of differences between boys and girls in the skills tapped by this task. The important differences between the accident rates for the two sexes cannot therefore be explained in terms of the skills examined here.

(4) The results were consistent across all the tasks and do not appear to be specific to any one of the methods studied.

These main findings appear to be consistent with Sandels' (1975) conclusion that children tend to fixate on elements of the traffic situation. However, in our tasks the children were consistent about the elements they fixated on. This implies that training needs to be designed to discourage the adoption of rigid strategies and encourage flexibility.

The results clearly have implications for the Green Cross Code. For example, the code does not instruct children on how to select a safe place to cross, nor is this normally regarded as an important aspect of road education. In fact, Foot et al. (1982) found that parents, teachers, road-safety educators and police when asked to indicate the most important rules children should be taught about road safety, relegated choosing of a safe spot where visibility was good to a secondary level of importance. Our results suggest that young children are largely unaware of the dangers posed by even extremely risky locations and are clearly in need of training on this aspect of good road behaviour. At the very least, they should be taught to identify locations which they should avoid at all costs. Our results suggest that young children simply cannot make such judgements for themselves.

The present findings appear to have a bearing on a current controversy concerning how best to train children to deal with features such as parked cars and junctions 
(Grayson, 1981). In some countries, children are encouraged to cross at junctions (on the assumption that vehicle speeds are lower there): in others, children are discouraged from using them because of their complexity. Similarly, children may be advised to cross well away from parked cars (as in the UK): or they may be taught to treat the edge of parked cars as a kerb that effectively reduces the width of the road. Our results would suggest that young children be discouraged from attempting to cross at such sites since they simply cannot see any inherent dangers in them. We cannot say whether this is true of more mature road users, including perhaps older children. Howarth and Repetto-Wright (1978), for instance, have obtained evidence that junctions in the absence of parked cars are safe for use by $8-10$-year-olds but not 5-6-year-olds. This suggests that the danger inherent in a site varies according to who is using it and again stresses the possible benefits of training in such skills.

The four age groups appeared to understand the tasks and certainly found them interesting. The various techniques were more or less equal in the effects obtained, suggesting that the table-top model may have potential as a simple and attractive training device that might be used in the classroom to improve at least some aspects of children's road knowledge and skill. Whilst in the end there can be no substitute for training in realistic situations, it is possible that preliminary training using models might provide a basis on which in situ training might build. We have already constructed and evaluated a short training programme using the model with encouraging results (Ampofo-Boateng, 1987). However, the skills acquired in this way were not tested in the real traffic environment, nor was their resilience over the longer term examined. We are now engaged on a much larger programme of research to develop and evaluate such a training procedure.

\section{Acknowledgements}

The authors wish to thank George Gillespie and Gerard Cummings of Glasgow Road Safety Division for their assistance in running the project. We also thank William Cheyne and David Lee for stimulating discussion and technical advice. Preparation of the manuscript was partly supported by ESRC grant X202252001 funded by General Accident Insurance under its Road User Behaviour Initiative.

\section{References}

Ampofo-Boateng, K. (1987). Children's perception of safety and danger on the road. Unpublished doctoral dissertation, University of Strathclyde.

Ampofo-Boateng, K. \& Thomson, J. A. (1990). Child pedestrian accidents: A case from preventive medicine. Health Education Research: Theory and Practice, 5 (2), 265-274.

Borke, H. (1984). Piaget's mountains revisited: Changes in the egocentric landscape. In M. Donaldson, R. Grieve \& C. Pratt (Eds), Early Childhood Development and Education: Readings in Psychology. Oxford: Basil Blackwell.

Cox, M. V. (1980). Visual perspective-taking in children. In T. Mischel (Ed.), Understanding Other Persons. Oxford: Basil Blackwell.

Department of Transport (1988). Road Accidents, Great Britain: The Casualty Report. London: HMSO. Donaldson, M. (1978). Children's Minds. Glasgow: Collins.

Foot, H. C., Chapman, A. J. \& Wade, F. M. (1982). Pedestrian accidents: General issues and approaches. In A. J. Chapman, F. M. Wade \& H. C. Foot (Eds), Pedestrian Accidents. Chichester: Wiley. 
Grayson, G. B. (1975). The Hampshire Cbild Pedestrian Study. Department of the Environment, Transport and Road Research Laboratory, Report 670. Crowthorne: TRRL.

Grayson, G. B. (1981). The identification of training objectives: What shall we tell the children? Accident Analysis and Prevention, 13, 169-173.

Gzech, S. M. \& Surber, C. F. (1985). Visual perspective-taking skills in children. Cbild Development, 56, $1204-1213$.

Howarth, C. I. \& Lightburn, A. (1980). How drivers respond to pedestrians and vice versa. In D. J. Oborne \& J. A. Levis (Eds), Human Factors in Transport Research 2. User Factors: Comfort, the Environment and Bebaviour. London: Academic Press.

Howarth, C. I. \& Repetto-Wright, R. (1978). The measurement of risk and attribution of responsibility for child pedestrian accidents. Safety Education, 144, 10-13.

Lee, D. N., Young, D. S. \& McLaughlin, C. M. (1984). A roadside simulation of road crossing for children. Ergonomics, 27, 1271-1281.

Morris, J. P. (1972). Road Safety Publicity: Quantifying the Effects of Public Service Advertising. London: Chantrey House.

ONSER (1982). Facteurs d'insécurité de l'enfant en zone urbaine: Méthodologie d'identification et de diagnostic. Cited in: OECD (1983). Transport Research - Traffic Safety of Children. Paris: OECD.

OECD (1983). Traffic Safety of Children. Paris: OECD.

Piaget, J. \& Inhelder, B. (1956). The Child's Conception of Space. London: Routledge \& Kegan Paul.

Richards, H. (1974). Sicherung von Schulwegen. In T. Rothengatter (1981). Traffic Safety Education for Young Children. An Empirical Approach. Lisse: Swets \& Zeitlinger.

Sandels, S. (1975). Children in Traffic. London: Elek.

Sheehy, N. P. \& Chapman, A. J. (1984). Accidents and safety. In A. Gale \& A. J. Chapman (Eds), Psychology and Social Problems. London: Wiley.

Singh, A. (1982). Pedestrian education. In A. J. Chapman, F. M. Wade \& H. C. Foot (Eds), Pedestrian Accidents. Chichester: Wiley.

Van der Molen, H. H. (1981). Child pedestrians' exposure, accidents and behaviour. Accident Analysis and Prevention, 13, 193-224.

Vinje, M. P. (1981). Children as pedestrians: Abilities and limitations. Accident Analysis and Prevention, $13,225-240$.

Young, D. S. \& Lee, D. N. (1987). Training children in road crossing skills using a roadside simulation. Accident Analysis and Prevention, 19, 327-341. 